$\sqrt{ }$

EDITOR'S

CHOICE

\title{
Intra-arterial chemotherapy for retinoblastoma in eyes with vitreous and/or subretinal seeding: 2-year results
}

\author{
David H Abramson, ${ }^{1}$ Brian P Marr, ${ }^{1}$ Ira J Dunkel, ${ }^{2}$ Scott Brodie, ${ }^{3}$ Emily C Zabor, ${ }^{4}$ \\ Sarah J Driscoll, ${ }^{1}$ Y Pierre Gobin ${ }^{5}$
}

${ }^{1}$ Ophthalmic Oncology Service, Memorial Sloan-Kettering Cancer Center, New York, New York, USA

2Department of Pediatrics, Memorial Sloan-Kettering Cancer Center, New York, New York, USA

${ }^{3}$ Department of Ophthalmology, Mt Sinai School of Medicine. New York, New York, USA ${ }^{4}$ Department of Epidemiology \& Biostatistics, Memorial Sloan-Kettering Cancer Center, New York, New York, USA ${ }^{5}$ Division of Interventional Neuroradiology, Department of Radiology, Neurosurgery and Neurology, Weill Cornell Medical College, New York, New York USA

\section{Correspondence to}

Dr David H Abramson, 70 East 66th Street, New York, NY

10021, USA;

abramsod@mskcc.org

Accepted 12 October 2011 Published Online First

3 November 2011

\section{ABSTRACT}

Background/aims To review the effectiveness of intraarterial chemotherapy for advanced intra-ocular retinoblastoma with vitreous and/or subretinal seeds in naive (untreated) and previously treated eyes.

Methods Retrospective study, approved by the institutional review board, of 76 eyes of 67 patients with retinoblastoma with subretinal and/or vitreous seeding treated with intra-arterial chemotherapy at Memorial Sloan-Kettering Cancer Center between May 2006 and August 2010

Results Despite advanced intraocular disease with seeding, the majority (56/76) of eyes were saved; $20 / 76$ eyes were enucleated. Among treatment-naive eyes, the 2-year probability of ocular salvage was $83 \% 195 \% \mathrm{Cl}$ $27 \%$ to $97 \%$ ) for eyes with subretinal seeding only, $64 \%$ (95\% Cl 24\% to $87 \%$ ) for eyes with vitreous seeding only, and $80 \%$ (95\% Cl $40 \%$ to $95 \%$ ) for eyes with both. Among eyes that received previous treatment and had progressed, the 2-year probability of ocular salvage was $50 \%(95 \% \mathrm{Cl} 15 \%$ to $78 \%$ ) for eyes with only subretinal seeding, $76 \%$ (95\% Cl 48\% to 91\%) for eyes with vitreous seeding only, and $54 \%$ (95\% Cl $20 \%$ to $79 \%$ ) for eyes with both. Nine of 29 naive eyes $(31 \%)$ were cured with intra-arterial (super-selective ophthalmic artery infusion of chemotherapy) chemotherapy alone.

Conclusion Unlike radiation or systemic chemotherapy, intra-arterial chemotherapy can usually prevent the need for enucleation in naive eyes with advanced intraocular retinoblastoma with seeding - especially if the seeding is subretinal. Treatment appears to be less effective in previously treated eyes when subretinal seeding is present (50\% at 2 years), but may be more effective in eyes that failed to respond to previous systemic chemotherapy and have only vitreous seeding.

\section{INTRODUCTION}

Although there are many different (and equally successful) strategies for curing retinoblastoma limited to the retina, ${ }^{1}$ all strategies for managing advanced intraocular retinoblastoma are disappointing. Reese recognised this and therefore classified group V eyes (Va involving half the retina and $\mathrm{Vb}$ with vitreous seeding) as 'very unfavorable'. The majority of group $\mathrm{V}$ eyes have always been enucleated primarily, and only $20-25 \%$ of treated eyes (with external beam irradiation) avoided enucleation. Multiagent chemotherapy for group V eyes has also been disappointing. Friedman et al reported that, after systemic chemotherapy, $75 \%$ of group V eyes progressed, ${ }^{3}$ and Antonelli et al noted that none of the unilateral group $V$ eyes treated in
Brazil could be salvaged after systemic chemotherapy. ${ }^{4}$ Kim et al (and others) have suggested that systemic chemotherapy be used only for group I-III eyes because of the disappointing results (and toxicity) in more advanced eyes. ${ }^{5}$

The situation is even worse for Reese-Ellsworth group $\mathrm{Vb}$ eyes. Most are enucleated at diagnosis, but, with careful case selection (after enucleating most of these eyes), we demonstrated a $50 \%$ salvage rate with primary external beam irradiation. Kaneko and Suzuki pointed out that systemic chemotherapy 'rarely cures vitreous seeds', Shields and colleagues demonstrated that the most important predictive factor for failure with systemic chemotherapy was seeding. ${ }^{8}$

Subretinal seeding was never part of the ReeseEllsworth classification scheme, so there are no published data on the success/failure of primary external beam irradiation for eyes with subretinal seeding. Subretinal seeding is part of the newer international classification scheme; however, group $D$ eyes (with vitreous and/or subretinal seeding $>3 \mathrm{~mm}$ from a tumour) generally respond poorly to systemic chemotherapy. Gunduz and colleagues reported a success rate of $36 \%$ for eyes with seeding, but did not distinguish between vitreous seeding, subretinal seeding and eyes containing both. ${ }^{9}$ The international classification does not put subretinal seeding in a different group from vitreous seeding, so there is no way to know the actual success of eyes treated in the modern chemotherapy world subcategorised by whether they have only vitreous seeds, only subretinal seeds, or a combination of both.

Seeding of any type in eyes that have been primarily treated with radiation or chemotherapy and progressed carries with it a dire prognosis for ocular salvage. Of Reese-Ellsworth group $V$ eyes that were initially treated with radiation and progressed, only $2.2 \%$ could be salvaged with a second course of external beam irradiation. ${ }^{10}$ The most encouraging report from England demonstrated that $29 \%$ of group Va eyes that failed to respond to systemic chemotherapy could be salvaged, but the authors stressed that they did not treat all eyes that failed to respond to chemotherapy, and enucleated some such eyes rather than try a course of salvage irradiation. ${ }^{11}$ Only three eyes with vitreous seeding (group $\mathrm{Vb}$ ) were salvaged.

We have previously reported on our experience with intra-arterial chemotherapy for the treatment of naive eyes and eyes that progressed despite systemic chemotherapy. ${ }^{12-14}$ In our report on our 4 -year experience with intra-arterial chemosurgery, we noted that, for group $\mathrm{V}$ naive eyes primarily 
treated with intra-arterial chemosurgery, the Kaplan-Meier estimate of 2-year event-free survival was $80.5 \%$. This group included patients in our initial institutional review board cohort who had advanced intraocular disease scheduled for enucleation. For group $\mathrm{V}$ eyes that had not responded to previous management (with systemic chemotherapy and/or external beam irradiation), we salvaged $51.5 \%$ of eyes at 4 years. That series, however, did not separate vitreous from subretinal seeds, so we undertook an analysis of all eyes with vitreous and/or subretinal seeding to determine the success, time course, and patient and ocular survival with intra-arterial chemotherapy as initial management and as salvage therapy for eyes with subretinal and/or vitreous seeds.

\section{MATERIALS AND METHODS}

This is a retrospective, single institution, institutional review board-approved review of all retinoblastoma eyes with seeding treated at Memorial Sloan-Kettering Cancer Center between May 2006 and August 2010. The technique for intra-arterial chemotherapy has been described previously in detail. ${ }^{15}$ Patients were evaluated with monthly examinations under anaesthesia with indirect ophthalmoscopy and RetCam imaging. The A and $B$ ultrasound scan and modified electroretinogram (ERG) protocol (previously described ${ }^{15}$ ) were performed when clinically indicated. All statistical analyses were conducted using SAS software, V.9.2. The Kaplan-Meier method was used to estimate time to enucleation separately for treatment-naive eyes and eyes that had received previous treatment. Median followup time was calculated for eyes that were not enucleated. The minimum length of follow-up for any patient was 1 year. Analyses were stratified by vitreous seeding only, subretinal seeding only, or both vitreous and subretinal seeding.

\section{RESULTS}

There were 76 eyes of 67 patients included in this study (nine patients had bilateral disease). Patient-level characteristics are presented in table 1 and eye-level characteristics are presented in table 2 . There were 20 enucleations overall, eight of which were in eyes with only vitreous seeding, five were in eyes with only subretinal seeding, and seven were in eyes with both vitreous and subretinal seeding. Median follow-up for surviving eyes was 2.04 years (range $0.19-5.04)$. Among treatment-naive eyes, the 2 -year probability of ocular salvage was $83 \%(95 \%$ CI $27 \%$ to $97 \%$ ) for eyes with subretinal seeding only, $64 \%$ (95\% CI $24 \%$ to $87 \%$ ) for eyes with vitreous seeding only, and 80\% (95\% CI 40\%

Table 1 Patient-level characteristics overall and by vitreous seeding (VS), subretinal seeding (SRS) or both

\begin{tabular}{lllll}
\hline & $\begin{array}{l}\text { VS only } \\
(\mathbf{n}=\mathbf{2 7})\end{array}$ & $\begin{array}{l}\text { SRS only } \\
(\mathbf{n}=\mathbf{1 3})\end{array}$ & $\begin{array}{l}\text { Both VS } \\
\text { and SRS } \\
(\mathbf{n}=\mathbf{2 7})\end{array}$ & $\begin{array}{l}\text { Overall } \\
(\mathbf{n}=\mathbf{6 7})\end{array}$ \\
\hline $\begin{array}{l}\text { Age, median } \\
\text { (IOR) }\end{array}$ & $\begin{array}{l}23.0 \\
(6.0-95.0)\end{array}$ & $\begin{array}{l}18.0 \\
(3.0-41.0)\end{array}$ & $\begin{array}{l}18.0 \\
(5.0-62.0)\end{array}$ & $\begin{array}{l}18.0 \\
(3.0-95.0)\end{array}$ \\
$\begin{array}{l}\text { Sex, N (\%) } \\
\text { Female }\end{array}$ & $14(51.9)$ & $3(23.1)$ & $19(70.4)$ & $36(53.7)$ \\
$\quad$ Male & $13(48.1)$ & $10(76.9)$ & $8(29.6)$ & $31(46.3)$ \\
$\begin{array}{l}\text { Family history, } \\
\text { N (\%) }\end{array}$ & & & & \\
$\quad \begin{array}{l}\text { No } \\
\text { Yes }\end{array}$ & $24(88.9)$ & $13(100.0)$ & $23(85.2)$ & $60(89.6)$ \\
$\begin{array}{l}\text { Years of } \\
\text { follow-up, } \\
\text { median (range) }\end{array}$ & $1.8(0.2-3.0)$ & $2.2(0.2-4.6)$ & $1.6(0.2-5.0)$ & $1.7(0.2-5.0)$ \\
\hline
\end{tabular}

to $95 \%$ ) for eyes with both. Among eyes that received previous treatment, the 2 -year probability of ocular salvage was $50 \%$ (95\% CI 15\% to 78\%) for eyes with subretinal seeding only, $76 \%$ (95\% CI $48 \%$ to $91 \%$ ) for eyes with only vitreous seeding, and $54 \%$ (95\% CI 20\% to $79 \%$ ) for eyes with both.

Two patients developed metastatic retinoblastoma (and have previously been reported on ${ }^{14}$ ) and are in remission. No patient died from disease, treatment-related complications or second cancers. No patient received external beam irradiation after intra-arterial chemotherapy.

Overall, 33 (43.4\%) eyes received only one drug, 33 (43.4\%) received two drugs, and $10(13.2 \%)$ received three drugs during treatment. The number of cycles was dictated by the clinical response. Eyes with the best response received the fewest number of cycles. The majority ( 51 cases $=67.1 \%$ ) received three cycles or fewer.

Of the eyes that came to enucleation, some were retained for as long as 2.6 years; the median time for retention was 8.7 months (range $0.9-30.8$ ).

\section{Electroretinogram}

Flicker ERGs $(30 \mathrm{~Hz})$ were available before and after treatment with super-selective ophthalmic artery infusion of chemotherapy (SSOAIC) in 72 eyes. Improvement or worsening of the ERG was defined as $>25 \mu \mathrm{V}$ or $<25 \mu \mathrm{V}$ change. Forty-one eyes were unchanged, 14 were better, and 17 were worse.

\section{Additional treatments}

Of the 76 eyes, 16 were cured with SSOAIC alone. Forty-three received supplemental laser, and 43 received supplemental

Table 2 Eye-level characteristics overall and by vitreous seeding (VS), subretinal seeding (SRS) or both

\begin{tabular}{|c|c|c|c|c|}
\hline & $\begin{array}{l}\text { VS only } \\
(\mathrm{n}=31)\end{array}$ & $\begin{array}{l}\text { SRS only } \\
(n=15)\end{array}$ & $\begin{array}{l}\text { Both VS } \\
\text { and SRS } \\
(n=30)\end{array}$ & $\begin{array}{l}\text { Overall } \\
(\mathrm{n}=76)\end{array}$ \\
\hline \multicolumn{5}{|l|}{ IC group, $\mathrm{N}(\%)$} \\
\hline C & $14(45.2)$ & $1(6.7)$ & $2(6.7)$ & $17(22.4)$ \\
\hline D & $14(45.2)$ & $12(80.0)$ & $23(76.7)$ & $49(64.5)$ \\
\hline $\mathrm{E}$ & $3(9.7)$ & $2(13.3)$ & $5(16.7)$ & $10(13.2)$ \\
\hline \multicolumn{5}{|l|}{ RE group, N (\%) } \\
\hline $5 \mathrm{~A}$ & $0(0.0)$ & $8(53.3)$ & $0(0.0)$ & $8(10.5)$ \\
\hline $5 B$ & $31(100.0)$ & $7(46.7)$ & $30(100.0)$ & $68(89.5)$ \\
\hline \multicolumn{5}{|l|}{ Previous treatment, $\mathrm{N}(\%)$} \\
\hline No & $9(29.0)$ & $6(40.0)$ & $14(46.7)$ & $29(38.2)$ \\
\hline Yes & $22(71.0)$ & $9(60.0)$ & $16(53.3)$ & $47(61.8)$ \\
\hline \multicolumn{5}{|c|}{ Type of previous treatment, $\mathrm{N}(\%)$} \\
\hline $\begin{array}{l}1-2 \text { systemic chemo } \\
\text { treatments }\end{array}$ & $5(22.7)$ & $2(22.2)$ & $2(12.5)$ & $9(19.1)$ \\
\hline $\begin{array}{l}3-6 \text { systemic chemo } \\
\text { treatments }\end{array}$ & $9(40.9)$ & $4(44.4)$ & $7(43.8)$ & $20(42.6)$ \\
\hline $\begin{array}{l}>6 \text { systemic chemo } \\
\text { treatments }\end{array}$ & $2(9.1)$ & $0(0.0)$ & $1(6.3)$ & $3(6.4)$ \\
\hline EBR only & $0(0.0)$ & 1 (11.1) & $0(0.0)$ & $1(2.1)$ \\
\hline $\begin{array}{l}\text { EBR + any systemic } \\
\text { chemo }\end{array}$ & $3(13.6)$ & $1(11.1)$ & $6(37.5)$ & $10(21.3)$ \\
\hline Local treatment only & $3(13.6)$ & $1(11.1)$ & $0(0.0)$ & $4(8.5)$ \\
\hline \multicolumn{5}{|l|}{ Number of drugs, $\mathrm{N}(\%)$} \\
\hline 1 & $12(38.7)$ & $7(46.7)$ & $14(46.7)$ & $33(43.4)$ \\
\hline 2 & $15(48.4)$ & $6(40.0)$ & $12(40.0)$ & $33(43.4)$ \\
\hline 3 & $4(12.9)$ & $2(13.3)$ & $4(13.3)$ & $10(13.2)$ \\
\hline \multicolumn{5}{|l|}{ Number of cycles, $\mathrm{N}(\%)$} \\
\hline$\leq 3$ & $19(61.3)$ & $12(80.0)$ & $20(66.7)$ & $51(67.1)$ \\
\hline$>3$ & $12(38.7)$ & $3(20.0)$ & $10(33.3)$ & $25(32.9$ \\
\hline
\end{tabular}

Chemo, chemotherapy; EBR, external beam irradiation; IC, international classification; $R E$, Reese-Ellsworth; SRS, sub-retinal seeds; VS, vitreous seeds. 
cryotherapy. Nine received plaques. Of the 29 naive cases, nine (31\%) received only SSOAIC. Fifteen received additional laser, 13 additional cryotherapy, and seven plaques.

\section{DISCUSSION}

Seeding of retinoblastoma is widely recognised as the most common reason for enucleation in naive or previously treated retinoblastoma in developed countries. In Reese's day, $75 \%$ of cases were group $\mathrm{V}$, and most were primarily enucleated. Of the primarily radiated cases, only $20 \%$ could be salvaged. ${ }^{15} \mathrm{He}$ did not publish results on success in group Va versus Group Vb (ie, with and without vitreous seeding), but success in group $\mathrm{Vb}$ eyes was even lower than the $20 \%$ figure. In those days, almost all cases of failed radiation resulted in enucleation, so they represent what we now refer to as 'naive' cases. As radiation techniques became more sophisticated, he (then Ellsworth and then Abramson) had experience with eyes that had received two and even three courses of radiation. ${ }^{10}$ Most eyes that did not respond to the first course of radiation were enucleated. Of the eyes that had vitreous seeds after the first course of radiation, only $2.2 \%$ were salvaged. Unfortunately, $35 \%$ of patients who received second and third courses of radiation died from metastatic retinoblastoma. ${ }^{10}$

Reese carried out most of his work with the direct ophthalmoscope and did not include subretinal seeding in his classification scheme. When the international classification scheme was introduced, it was recognised that subretinal seeding was an important predictor of failure after primary treatment with systemic, multiagent chemotherapy. Group $\mathrm{C}$ eyes have 'minimal subretinal or vitreous seeding' and are defined as having 'subretinal fluid, present or past, without seeding involving up to $1 / 4$ retina, local fine vitreous seeding may be present close to discrete tumour and local subretinal seeding less than $3 \mathrm{~mm}$ (2DD) from the tumour'. Group D eyes have some (not necessarily all) of the following features: 'diffuse disease with significant vitreous or subretinal seeding'. They are defined as: 'subretinal fluid present or past without seeding, involving up to total retinal detachment, diffuse or massive vitreous disease may include 'greasy' seeds or avascular tumour masses, and diffuse subretinal seeding may include subretinal plaques or tumour nodules'. Multiple studies have confirmed that group D eyes fare less well than group $\mathrm{C}$ eyes, and statements such as 'systemic chemotherapy can rarely cure vitreous seeding' ${ }^{16}$ are common in the literature. Using a slightly different new classification scheme, Shields et al reported that retinoblastoma recurred in $45 \%$ of group $C$ and D eyes. ${ }^{17}$ They emphasised that, of naive eyes with subretinal seeds treated with multiagent systemic chemotherapy, retinoblastoma recurred in $62 \%$ within 3 years. In another report from Philadelphia, these authors emphasised that the "presence of vitreous seeds and subretinal seeds... were factors associated with the need for enucleation'. Of 75 eyes with group $V$ disease, 32 required additional radiation and 32 were enucleated (some required both). ${ }^{18}$ These results were echoed by Beck et al, who noted that systemic chemotherapy for groups IV and V was 'disappointing'. ${ }^{19}$ In the past year, a $100 \%$ failure rate (requiring enucleation) of group D eyes managed with systemic chemotherapy was reported from China. ${ }^{20}$

There has been more than one international retinoblastoma classification scheme published and used in the past 10 years, causing some confusion in interpreting data. ${ }^{21}$ Nonetheless, even earlier series by investigators in many countries produced discouraging results for group $\mathrm{V}$ (or D) eyes. Of 24 such eyes treated in England, 20 required radiation and six required enucleation. $^{22}$ Of 21 such eyes, Murphree et al reported the need for radiation in seven eyes and enucleation in $17 .^{23}$ Of six such eyes, Greenwald et al reported the need for radiation in five and enucleation in three. ${ }^{24}$ Rodriguez-Galindo et al reported that, of 15 such eyes, eight required radiation and eight enucleation. ${ }^{25}$

Although comparisons are difficult because definitions throughout these studies are not standardised, our results are both notable and informative. Although eyes with subretinal seeding generally fare poorly with systemic chemotherapy, they fared better with intra-arterial chemotherapy. Overall, 83\% of such eyes that were treatment naive and $50 \%$ of such eyes that had been previously treated were estimated to be salvaged without radiation at 2 years. Intra-arterially treated eyes with vitreous seeding alone did well compared with older reports of systemic chemotherapy, with estimated 2 -year salvage rates of $64 \%$ for treatment naive and $76 \%$ for previously treated eyes. Although the success rate for eyes with both subretinal and vitreous seeds that had been previously treated was low $(54 \%$ at 2 years), considering that this group had already failed to respond to previous management with systemic chemotherapy, focal treatments and occasionally radiation with a plaque or external beam and faced enucleation, such salvage rates represent an important step in retinoblastoma management.

Vitreous and subretinal seeding remain a challenge for clinicians treating intraocular retinoblastoma, but the success of intra-arterial chemotherapy in salvaging eyes (without the need for external beam irradiation) is encouraging. Most eyes with either vitreous seeding and/or subretinal seeding were saved with intra-arterial chemotherapy. These are precisely the eyes that usually do not respond to primary systemic chemotherapy or external beam irradiation. Although the success rate may be lower in previously treated eyes that progress after systemic chemotherapy and/or external beam irradiation, enucleation can be avoided in the majority of such eyes.

Finally, eyes that failed to respond to SSOAIC treatment and progressed to enucleation were retained for as long as $21 / 2$ years (median 8.7 months). In some cases, it was the patient's remaining eye. It is hoped that these additional months or years of vision were of value to these patients, even though the eye could not ultimately be saved.

Acknowledgments We thank Anabela Rodrigues for her assistance.

Funding This work was supported in part by grants from the Fund for Ophthalmic Knowledge, Inc (New York) and the Alcon Research Institute (Houston, Texas).

\section{Competing interests None.}

Ethics approval Ethics approval was provided by IRB Memorial Sloan-Kettering Cancer Center, New York.

Contributors DHA: concept, data collection, writing, funding. BPM: critical revisions patient care, data collection. IJD: critical revisions, data collection. SB: ERG data, critical revisions, data collection. EZ: data collection, statistics. SJD: data collection and analysis. YPG: concept, data collection, writing, critical revisions.

Provenance and peer review Not commissioned; externally peer reviewed.

\section{REFERENCES}

1. Kim JW, Abramson DH, Dunkel IJ. Current management strategies for intraocular retinoblastoma. Drugs 2007;67:2173-85.

2. Reese AB. Tumors of the Eye. 2nd edn. New York, NY: Harper \& Row, 1963:368-77.

3. Friedman DL, Himelstein B, Shields CL, et al. Chemoreduction and local ophthalmic therapy for intraocular retinoblastoma. J Clin Oncol 2000; 18:12-17.

4. Antonelli CB, Ribeiro KC, Steinhorst F, et al. Treatment of retinoblastoma patients with chemoreduction plus local therapy: experience of the AC Camargo Hospital, Brazil. J Pediatr Hematol Oncol 2006;28:342-5. 
5. Kim JH, Yu YS, Khwarg Sl, et al. Clinical result of prolonged primary chemotherapy in retinoblastoma patients. Korean J Ophthalmol 2003;17:35-43.

6. Abramson DH, Beaverson KL, Chang ST, et al. Outcome following initial external beam radiotherapy in patients with Reese-Ellsworth group Vb retinoblastoma. Arch Ophthalmol 2004;122:1316-23.

7. Kaneko A, Suzuki S. Eye-preservation treatment of retinoblastoma with vitreous seeding. Jpn J Clin Oncol 2003;33:601-7.

8. Shields CL, Honavar SG, Meadows AT, et al. Chemoreduction plus focal therapy for retinoblastoma: factors predictive of need for treatment with external beam radiotherapy or enucleation. Am J Ophthalmol 2002;133:657-64.

9. Gunduz K, Gunalp I, Yalcindag N, et al. Causes of chemoreduction failure in retinoblastoma and analysis of associated factors leading to eventual treatment with external beam radiotherapy and enucleation. Ophthalmology 2004;111:1917-24.

10. Abramson DH, Ellsworth RM, Rosenblatt M, et al. Retreatment of retinoblastoma with external beam irradiation. Arch Ophthalmol 1982;100:1257-60.

11. Chan MPY, Hungerford JL, Kingston JE, et al. Salvage external beam radiotherapy after failed primary chemotherapy for bilateral retinoblastoma: rate of eye and vision preservation. Br J Ophthalmol 2009;93:891-4.

12. Abramson DH, Dunkel IJ, Brodie SE, et al. A phase $\mathrm{I} / \mathrm{II}$ study of direct intraarterial (ophthalmic artery) chemotherapy with melphalan for intraocular retinoblastoma initial results. Ophthalmology 2008;115:1398-404.

13. Abramson DH. Super selective ophthalmic artery delivery of chemotherapy for intraocular retinoblastoma: 'chemosurgery' the first Stallard lecture. $\mathrm{Br} \mathrm{J}$ Ophthalmol 2010;94:396-9.

14. Gobin YP, Dunkel IJ, Marr BP, et al. Intra-arterial chemotherapy for the management of retinoblastoma: four-year experience. Arch Ophthalmol 2011;129:732-7.

15. Reese AB, Ellsworth RM. The evaluation and current concept of retinoblastoma therapy. Trans Am Acad Ophthalmol Otolaryngol 1963:67:164-72.
16. Suzuki S, Kaneko A. Management of intraocular retinoblastoma and ocular prognosis. Int J Clin Oncol 2004;9:1-6.

17. Shields CL, Mashayekhi A, Cater J, et al. Chemoreduction for retinoblastoma: analysis of tumor control and risks for recurrence in 457 tumors. Trans Am Ophthalmol Soc 2004;102:35-45.

18. Shields CL, Honavar SG, Shields JA, et al. Factors predictive of recurrence o retinal tumors, vitreous seeds and subretinl seeds following chemoreduction for retinobastoma. Arch Ophthal 2002;120:460-4.

19. Beck NM, Balmer A, Dessing P, et al. First-Line Chemotherapy with local treatment can prevent external-beam irradiation and enucleation in low-stage intraocular retinoblastoma. J Clin Oncol 2000;18:2881-6.

20. Qian J, Xue K, Gao YJ, et al. [Clinical therapeutic efficiency of chemoreduction and local therapy for children with retinoblastoma]. Zhongua Yan Ke Za Zhi 2010;46:312-16

21. Novetsky DE, Abramson DH, Kim JW, et al. Published international classification of retinoblastoma (ICRB) definitions contain inconsistencies - an analysis of impact. Ophthalmic Genet 2009:30:40-4.

22. Kingston JE, Hungerford JL, Madreperla SA, et al. Results of combined chemotherapy and radiotherapy for advanced intraocular retinoblastoma. Arch Ophthalmol 1996:114:1339-43.

23. Murphree AL, Villablanca JG, Deegan WF 3rd, et al. Chemotherapy plus local treatment in the management of intraocular retinoblastoma. Arch Ophthalmol 1996;114:1348-56.

24. Greenwald MJ, Goldman S, Strauss LC. CCombined chemoreduction and adjuvant treatment for intraocular retinoblastoma. Ophthalmology 1998;105:1579-81.

25. Rodriguez-Galindo C, Wilson MW, Haik BG, et al. Treatment of intraocular retinoblastoma with vincristine and carboplatin. J Clin Oncol 2003; 21:2019-25

\section{British Journal of Ophthalmology alerts}

Sign up for our electronic table of contents alert and you will never miss new issues of British Journal of Ophthalmology when published online. Stay ahead and up to date by visiting bjo.bmj.com. 